\title{
Evaluation of Solar Hybrid Power Systems and its Efficacy in the UAE Market
}

\author{
Zaki Iqbal ${ }^{a, *}$ and Gorkem Soyumer ${ }^{b}$ \\ ${ }^{a}$ RAK Research and Innovation Center, American University of Ras Al Khaimah, UAE \\ ${ }^{b}$ Enerwhere Sustainable Energy, Dubai, UAE
}

\begin{abstract}
Due to rapid industrialization and urbanization, the supplying of the electricity demand using hybrid (solar and diesel) systems has attracted great interest in UAE [1]. In this paper, comparisons of electricity generation with three configurations has been studied, starting from the base scenario of i) multiple stand-alone hybrid systems which is upgraded to ii) AC-coupled mini-grid and iii) DC-coupled mini-grid. The available energy supply, storage and transmission units as well as internal electrical demand of RAKRIC's open air R\&D laboratory, Solab, have constituted the basis of the calculations. The cost estimates for the major components forming mini-grids have been found out to be comparable for AC-coupled and DC-coupled networks. Although the results provided in this paper do not apply universally since feasibility of electricity transmission and storage is notably affected by the positions of supply and load centers along with the generation and consumption time profiles. Solar hybrid power system can be the next option for the UAE fast growing market.
\end{abstract}

Keywords: Hybrid Electricity, AC Coupled, DC Coupled, Stand-Alone Off-Grid, Homer

\section{Introduction}

UAE's energy demand is growing rapidly with the onset of urbanization. It has seen an economic growth of $10 \%$ annually since 2006 [2]. The energy demand has been growing up by more the $9 \%$ with diesel fired energy production on the rise [2]. The cost, availability and security of energy resources play major role while selecting the technology for electricity production. Through the efforts of regulatory bodies and technology providers, users are becoming aware that solar diesel hybrid systems deliver significant savings in the levelized cost of electricity generation. Nevertheless, the economic advantages of hybrid systems are experienced at greater extent with the larger mini-grids because of the scale effect in the cost of photovoltaic systems. The use of PV diesel hybrid power systems (PVDHS) in remote parts of the world has been encouraged by the International Energy Agency with its Task Report 11 dedicated to the mini-grids [3].
In the light of this task, a number of guidelines have been generated providing comprehensive insights on the design and stability of mini-grids as well as the strategies assuring the sustainability of the project managements [4]. Despite of the vast availability of technical, social and environmental publications related to the implementation of PVDHS, little is known about the economics of forming Solar Hybrid mini-grids. The substantial contribution of this study will be its guiding role for the preliminary cost analysis of upgrading stand-alone systems to mini-grids. In this paper, 2) existing off-grid stand-alone system and electricity utilization in Solab will be briefly introduced, then 3) AC-coupled and DC-coupled as the two mini-grid network types will be illustrated. To explore the economical dimensions, 4) cost of transforming the existing standalone system in Solab into the solar hybrid power system will be estimated. Last part will be 5) conclusion for economic comparison of mini-grid networks with multiple stand-alone systems.

\footnotetext{
${ }^{*}$ Corresponding author

Email: zaki.Iqbal@aurak.ac.ae

(C) 2016 International Association for Sharing Knowledge and Sustainability

DOI: $10.5383 /$ ijtee.11.01.011
} 


\section{Off-Grid Standalone System and Load Profile of Research Center}

Figure 1 shows that electricity in Solab was previously produced by stand-alone solar PV and battery systems at 4 research centers (desalination, cooling, photovoltaic and calorimeter). As the main supplier of 2 centers (CSP center and Solar Island) and central backup unit, $50 \mathrm{kVA}$ diesel generator is connected to each center through the existing cabling network. Diesel generator in the previous setup was manually integrated into the network.

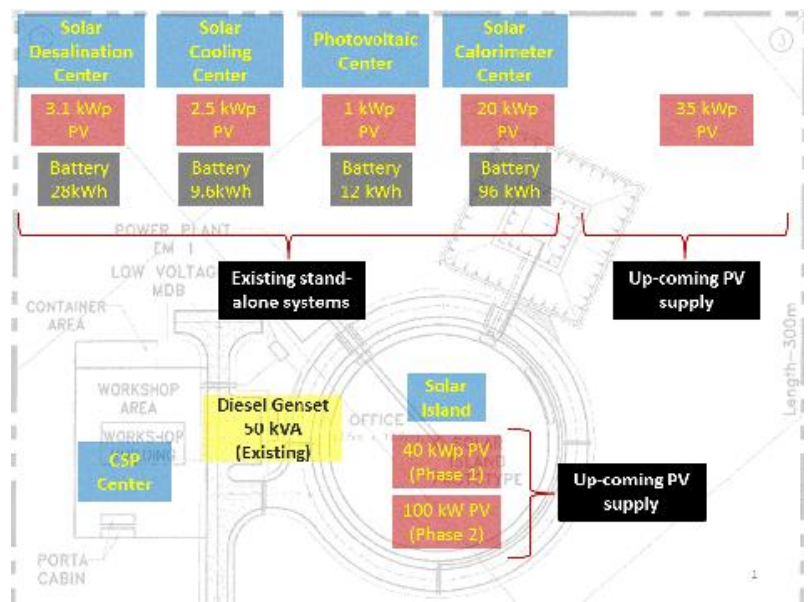

Figure 1: The Existing off-Grid Stand-Alone PVDHS in Solab

Load profile was calculated by designing the Load profile algorithm. The estimation of the hourly electrical demands at each center can be seen in Figure 2. Taking load estimates along with the supply from diesel generator and PV modules, operation of batteries and excess electricity generation have been modeled over a year by using the hybrid energy simulation software, Homer.

Homer offers to users to specify DC and AC bus which is crucial part of modeling AC-coupled and DC-coupled networks [5]. 2009 climate data measured at RAKRIC's weather station has been used as input to software. The results of the simulations are presented in Figure 3.As seen from the graphs, significant amount of excess electricity is lost in stand-alone systems where energy transfer is not allowed between centers as can be seen in the Table 1 .

According to the summary of total energy balance given in Table 1 , on average each day almost $100 \mathrm{kWh}$ of electricity is supplied by diesel generator while $220 \mathrm{kWh}$ excess generation is being lost. As a result, cost of electricity generation can be greatly reduced by integrating stand-alone systems in a mini-grid where storage and dispatch is managed more efficiently. This way the excess electricity will be valorized which will also lead to reduction in the diesel supply.
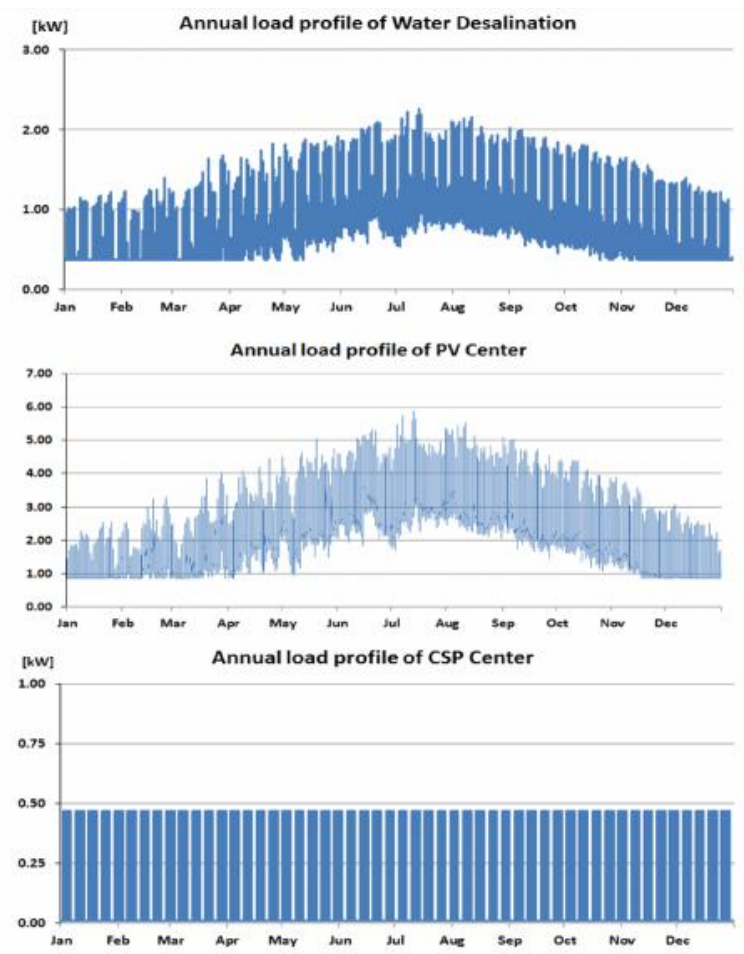

[kW] Annual load profile of Solar Cooling
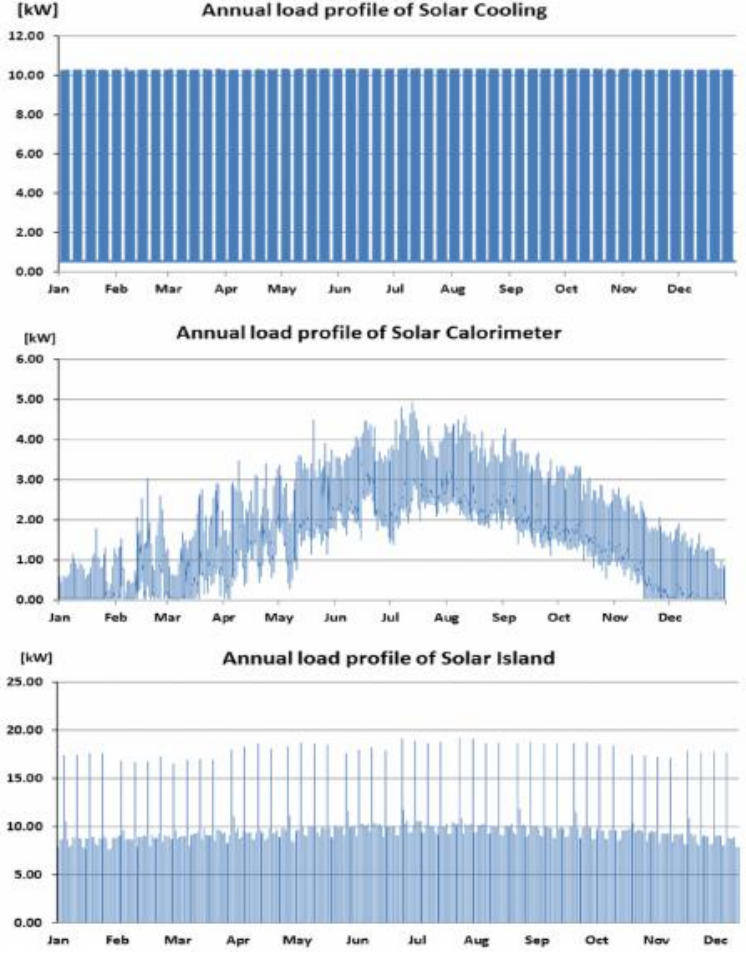

Figure 2: Electricity Load Profile Generated for each Center in Solab over a Year 

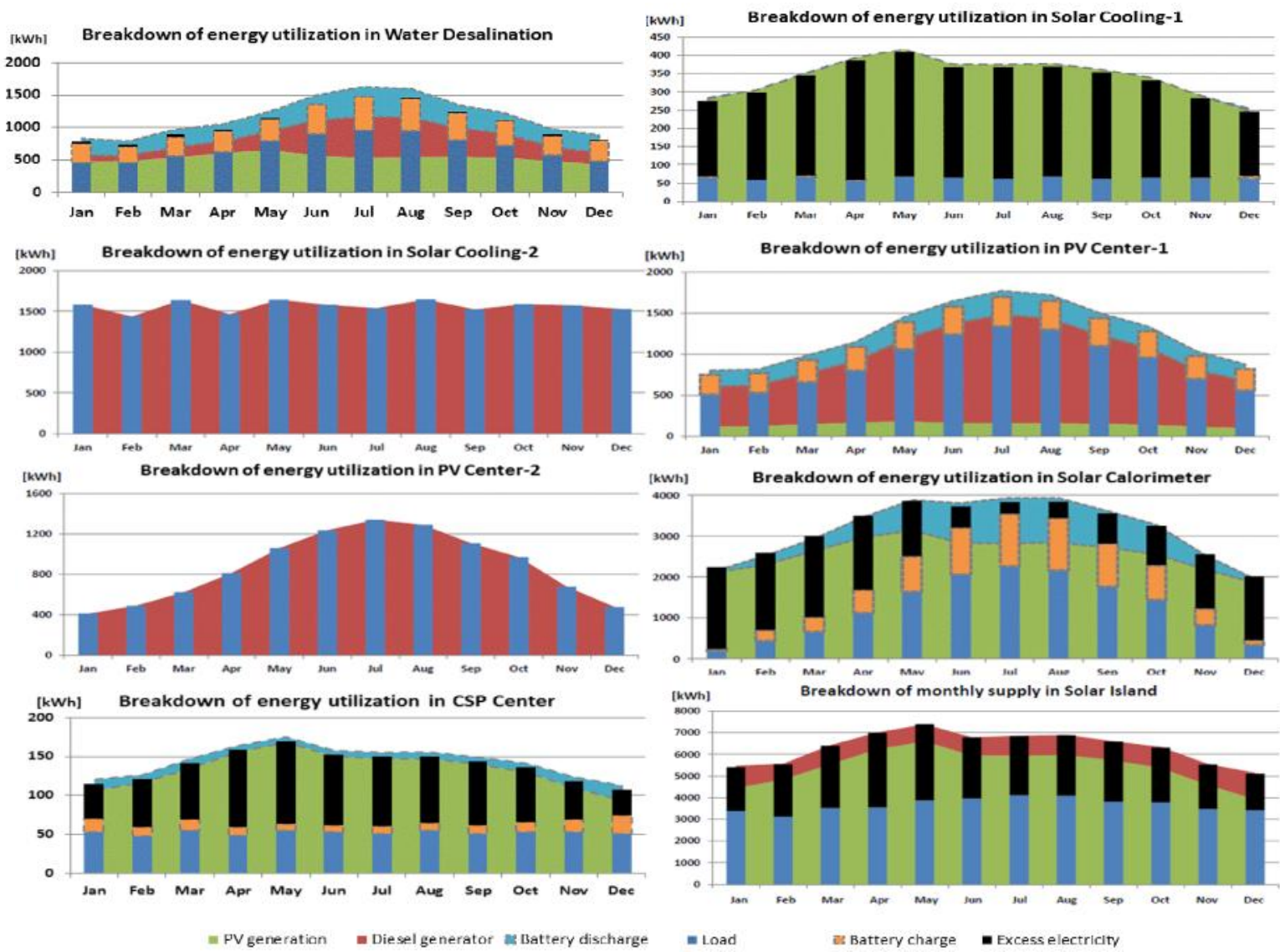

Figure 3: Electricity Utilization Profiles at each Center in Solab over a Year

Table 1: The Electricity Balance at each Center in Solab

\begin{tabular}{|c|c|c|c|c|c|c|c|c|}
\hline & \multicolumn{3}{|c|}{ PV Supply } & \multirow{2}{*}{\begin{tabular}{|c|} 
Diesel \\
Supply \\
Average \\
Energy
\end{tabular}} & \multicolumn{3}{|c|}{ Electrical Load } & \multirow{2}{*}{$\begin{array}{c}\text { Excess } \\
\text { Electricity } \\
\text { Average Energ }\end{array}$} \\
\hline & \begin{tabular}{|l|} 
Average \\
Energy
\end{tabular} & $\begin{array}{l}\text { Average } \\
\text { Power }\end{array}$ & $\begin{array}{l}\text { Peak } \\
\text { Power }\end{array}$ & & $\begin{array}{l}\text { Average } \\
\text { Energy }\end{array}$ & $\begin{array}{l}\text { Average } \\
\text { Power }\end{array}$ & $\begin{array}{l}\text { Peak } \\
\text { Power }\end{array}$ & \\
\hline & {$[\mathrm{kWh} / \mathrm{d}]$} & {$[\mathrm{kW}]$} & {$[\mathrm{kW}]$} & {$[\mathrm{kWh} / \mathrm{d}]$} & {$[\mathrm{kWh} / \mathrm{d}]$} & {$[\mathrm{kW}]$} & {$[\mathrm{kW}]$} & {$[\mathrm{kWh} / \mathrm{d}]$} \\
\hline Water Desal. & 17.49 & 0.73 & 2.63 & 10.51 & 22.43 & 0.94 & 226 & 0.39 \\
\hline PV Center & 0 & 0 & - & 28.69 & 28.69 & 1.19 & 2.65 & . \\
\hline Security & 0 & 0 & 0 & 15.5 & 15.5 & 0.64 & 124 & - \\
\hline Calorimeter & 89.28 & 3.72 & 16.14 & 0 & 40.99 & 17 & 495 & 40.57 \\
\hline Cooling & 145.17 & 6.04 & 26.24 & 8.35 & s3.38 & 2.22 & 9.88 & 95.13 \\
\hline Solar island & 17.57 & 7.44 & 32.28 & 36.41 & 120.99 & 5.04 & 19.23 & 80.58 \\
\hline CSP & 。 & $\circ$ & 。 & 3.39 & 3.39 & 0.07 & 0.33 & . \\
\hline \multicolumn{4}{|c|}{ Total } & 02.8 & \multicolumn{3}{|c|}{ Total } & 220.6 \\
\hline
\end{tabular}

\section{Two Possible Mini-Grid Networks: AC-Coupled and DC-Coupled}

Two principal technological configurations exist for hybrid mini-grid networks [6]. The main difference between ACcoupled and DC-coupled is the bus line which is connecting the electricity generating components.

AC-Coupled Network: In AC-coupled networks, as given in Figure $4 \mathrm{a}, \mathrm{AC}$ bus line connects the DC-AC grid inverters of photovoltaic panels and diesel generator [6].

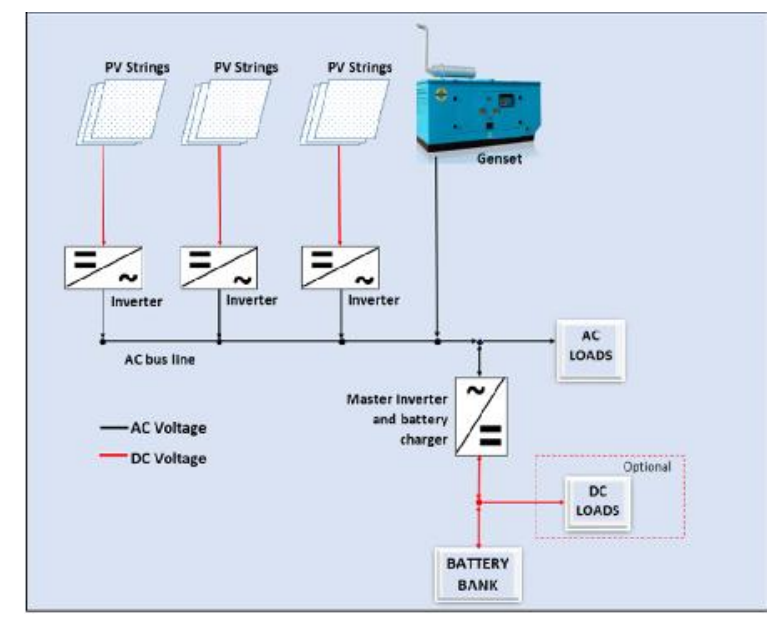

Figure 4a: AC-Coupled Mini-Grid Network

Master inverter with battery charger forms the grid through stabilizing the voltage. Batteries are vital components to balance the supply and demand all the times. During the times of demand higher than load, the deficit amount is provided by the energy stored in the batteries, until the state of charge falls down to lower set limit. Beyond that, diesel generator is switched on through an automatic generator contactor. When supply is 
higher than demand, the balance is stored in the batteries until state of charge reaches to the upper set limit. After that, the master inverter starts to increase the frequency which induces gradual falls in the output of grid inverters.

\section{The Advantages of AC-Coupled Networks [6]:}

- Flexibility in the placement of solar panels due to avoiding high cost of DC-cablings of PV panels,

- Lower cable cost for power transmission (smaller diameter and lower in quantity),

- Higher PV to grid efficiency through removing a conversion step at battery,

- Higher PV to load efficiency during the time only load matches generation (no loss at batteries),

- Only during the times load is not matching generation, power will be lost in the conversion step occurring at batteries.

\section{DC-Coupled Network:}

Figure $4 \mathrm{~b}$ highlights the connection of electricity generators on DC bus line in the case of DC-coupled networks [5]. Photovoltaic panels are coupled to bus line through charge controllers, due to the absence of master equipment that is regulating the charging of batteries. The logic of energy management works in the parallel way to AC-coupled networks. The biggest difference is the supply and demand balanced without using a frequency control. Master inverter itself supplies electricity which equal to the instantaneous demand.

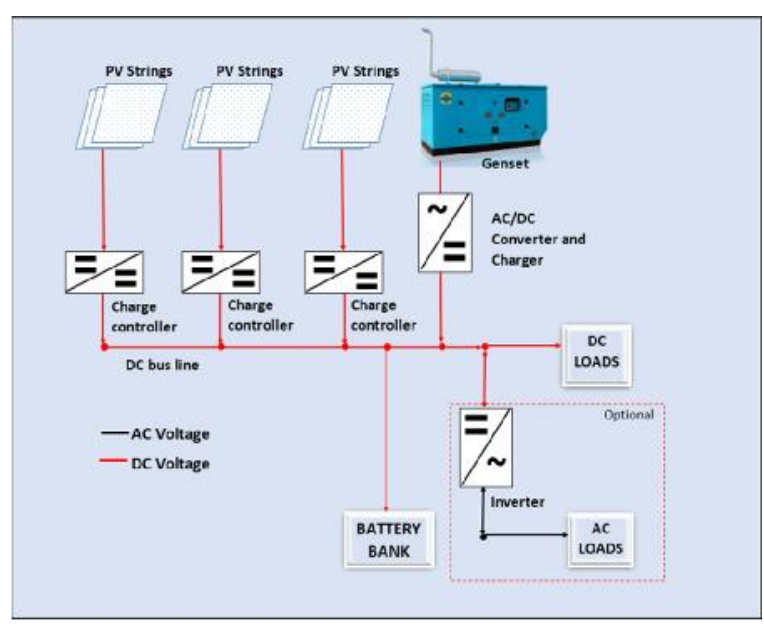

Figure 4b: DC-Coupled Mini-Grid Network

\section{The Advantages of DC-Coupled Networks:}

- For the same generated power, lower cost charge controllers are deployed relative to grid tie inverters.

- Simpler DC-AC inverters are sufficient as there is no need to use a master inverter communicating to grid inverters.

- No need for inverters in case of DC loads.

Mini-grid networks can be established by combining the existing components of stand-alone system. However, this also requires additional investment for infrastructural upgrades such as repositioning the distribution panels and recabling of DC and $\mathrm{AC}$ wires. Moreover, master inverter constitutes the significant part of investment which is essential for voltage stabilization in the mini-grid. On the other hand, such expenses result in significant savings since the electricity generated in stand-alone systems are more efficiently stored and dispatched in mini-grids. Consequently, excess electricity and diesel consumption are minimized.

\section{Economics Related to Developing the Solar Hybrid Power System}

\section{AC-Coupled Network:}

One of the issues faced while forming a mini-grid in Solab was the distance of around $180 \mathrm{~m}$ between Solar Island, CSP Center and the rest of Solab as seen in Figure 1. To connect each of PV plants within a single mini-grid without relocating them, $180 \mathrm{~m}$ of cable is needed to be mounted. However, the solution was more cost effective for AC-coupled network as it requires ACcables existed in the cabling network of back up diesel generator.

Component sizes resulting in the lowest levelized cost of electricity generation have been calculated as given in Table 2 . Optimal size of each component is noted in the last column which is the sum of existing components and the ones needed to be invested for the upgrading the stand-alone systems to ACcoupled network, indicated as "relevant".

Table 2: Ideal Size of AC-Coupled Network Components According to Homer Optimization and their Corresponding Costs

\begin{tabular}{|c|c|c|c|c|c|}
\hline Ac-coupled & & & Existing & Relevant & Total \\
\hline \multirow{2}{*}{ Battery } & \multicolumn{2}{|c|}{ kWh } & 150 & 60 & 210 \\
\hline & \multicolumn{2}{|c|}{$\$$} & 20003 & 8001 & 28004 \\
\hline Unit price & $\$ / \mathrm{kWh}$ & 133 & & & \\
\hline \multirow{2}{*}{ PV system (DC) } & \multicolumn{2}{|c|}{$k W p$} & 100 & 0 & 100 \\
\hline & \multicolumn{2}{|c|}{$\$$} & 71624 & 0 & 71624 \\
\hline Unit price & $\$ / \mathrm{kW}$ & 716 & & & \\
\hline \multirow{2}{*}{ Grid Tie inverter } & \multicolumn{2}{|c|}{ kWn } & 0 & 100 & 100 \\
\hline & \multicolumn{2}{|c|}{$\$$} & 0 & 47956 & 47956 \\
\hline Unit price & $\$ / \mathrm{kW}$ & 480 & & & \\
\hline \multirow{2}{*}{ Hybrid inverter } & \multicolumn{2}{|c|}{ kWn } & 0 & 20 & 20 \\
\hline & \multicolumn{2}{|c|}{$\$$} & 0 & 10899 & 10899 \\
\hline Unit price & $\$ / \mathrm{kW}$ & 545 & & & \\
\hline \multirow{2}{*}{ Combiner Box } & \multicolumn{2}{|c|}{ kW } & 100 & 0 & 100 \\
\hline & \multicolumn{2}{|c|}{$\$$} & 28300 & 0 & 28300 \\
\hline Unit price & $\$ / k W$ & 283 & & & \\
\hline Total & \multicolumn{2}{|c|}{$?$} & 119927 & 66856 & 186783 \\
\hline
\end{tabular}

In Solab, upgrading the multiple stand-alone systems to an ACcoupled mini-grid costs almost $\$ 67000$ (excluding the construction fee that has to be paid to the technicians and cost of adjusting AC-cabling). In Figure 5, the utilization of electricity with AC-coupled network is represented. In this configuration, daily diesel supply is more than $90 \%$ reduced to from $102 \mathrm{kWh}$ to $9.6 \mathrm{kWh}$. Additionally, through more efficient storage and dispatch, daily excess electricity generation has come down to $98.9 \mathrm{kWh}$ from $220 \mathrm{kWh}$. Yearly savings from diesel consumption is almost $\$ 12800$. 


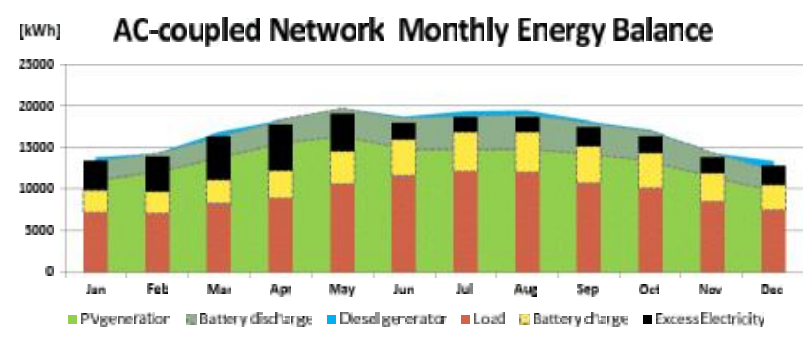

Figure 5: Monthly Electricity Utilization over a year in Solab with AC-Coupled Network

For Solab, unifying all the stand-alone PV plants within a single DC-coupled mini-grid has not been found technically feasible. The reason is the long distance $(180 \mathrm{~m})$ from Solar Island and CSP center to the rest of Solab. As introduced in the previous section, electricity generators are connected by DC cables on a $\mathrm{DC}$ bus line. This requires investing on high cost DC-cables to transfer the output of $40 \mathrm{kWp} \mathrm{PV}$ power plant. The other solution would be moving $40 \mathrm{kWp}$ power plant to a closer area. However, modules have to be mounted on the azimuth tracking system of Solar Island. So the only feasible solution was to form two non-interacting DC-coupled mini-grids. For this reason, centers have been distributed to two mini-grid zones as proposed in Table 3.

Table 3: Distribution of Centers to Two DC-Coupled Mini-Grid Zones



Minimizing diesel supply and excess electricity generation separately for two DC-coupled mini-grids is the objective of upgrading the stand-alone systems. The only differences made are adding the charge controllers into the mini-grid and removing the grid inverters from the mini-grid. Minimum PV capacity if fixed at $60 \mathrm{kWp}$ in Zone 1 and $40 \mathrm{kWp}$ in Zone 2. The total size of batteries in two zones is kept greater than 150 $\mathrm{kWh}$ because it is the capacity in present. The results of Homer simulations showing the optimum size of components for two zones are displayed in Table 4.

The relevant cost of DC-coupled mini-grids contains the charge controller regulating the output of $80 \mathrm{kWp} \mathrm{PV}$ plant because of the existing charge controllers installed on $20 \mathrm{kWp} \mathrm{PV}$ modules. This brings significant cost advantage to DC-coupled mini-grids given the more costly grid inverters employed in AC-coupled mini-grid. On the other hand, $45 \mathrm{~kW}$ of hybrid inverter (master) is needed in comparison to $20 \mathrm{~kW}$ in AC-coupled. Also, DCcoupled mini-grids require totally $135 \mathrm{kWh}$ additional battery storage. Consequently, the cost advantage of DC-coupled minigrids arising from the cheaper charge controllers are balanced off with their need for larger size master inverter and battery storage. Finally, total relevant investment requirement of DCcoupled network is $\$ 64000$.

According to Figure 6, Total daily diesel supply is $11 \mathrm{kWh}$ and excess electricity is $99.4 \mathrm{kWh}$. Therefore yearly savings from diesel consumption is calculated as $\$ 12620$.

Table 4: Ideal Size of DC-Coupled Network Components for Zone 1 and Zone 2 According to Homer Optimization and their Corresponding Costs

\begin{tabular}{|c|c|c|c|c|c|}
\hline \multicolumn{3}{|l|}{ DC-coupled Zone 1} & Existing & Relevant & Total \\
\hline \multirow{2}{*}{ Battery } & \multicolumn{2}{|c|}{ kWh } & 150 & 30 & 180 \\
\hline & \multicolumn{2}{|c|}{$\$$} & 20003 & 4001 & 24004 \\
\hline Unit price & $\$ / \mathbf{k W h}$ & 133 & & & \\
\hline \multirow{2}{*}{ PV system } & \multicolumn{2}{|c|}{$k W p$} & 60 & 0 & 60 \\
\hline & \multicolumn{2}{|c|}{$\$$} & 42974 & 0 & 42974 \\
\hline Unit price & $\$ / \mathbf{k W}$ & 716 & & & \\
\hline \multirow{2}{*}{ Charge Controller } & \multicolumn{2}{|c|}{ kW } & 20 & 40 & 60 \\
\hline & \multicolumn{2}{|c|}{$\$$} & 5341 & 10681 & 16022 \\
\hline Unit price & $\$ / \mathbf{k W}$ & 267 & & & \\
\hline \multirow{2}{*}{ Hybrid inverter } & \multicolumn{2}{|c|}{ kWn } & 0 & 25 & 25 \\
\hline & \multicolumn{2}{|c|}{$\$$} & 0 & 13624 & 13624 \\
\hline Unit price & $\$ / \mathbf{k W}$ & 545 & & & \\
\hline \multirow{2}{*}{ Combiner Box } & \multicolumn{2}{|c|}{ kW } & 60 & 0 & 60 \\
\hline & \multicolumn{2}{|c|}{$\$$} & 16980 & 0 & 16980 \\
\hline Unit price & $\$ / \mathrm{kW}$ & 283 & & & \\
\hline Total & & & 85298 & 28306 & 36 \\
\hline
\end{tabular}

\begin{tabular}{|c|c|c|c|c|c|}
\hline \multicolumn{3}{|l|}{ DC-coupled Zone 2} & Existing & Relevant & Total \\
\hline \multirow{2}{*}{ Battery } & \multicolumn{2}{|c|}{ kWh } & $\overline{0}$ & 105 & 105 \\
\hline & \multicolumn{2}{|c|}{$\$$} & 0 & 14002 & 14002 \\
\hline Unit price & \$/kWh & 133 & & & \\
\hline \multirow{2}{*}{ PV system (DC) } & \multicolumn{2}{|c|}{$k W p$} & 40 & $\mathbf{0}$ & 40 \\
\hline & \multicolumn{2}{|c|}{$\$$} & 28650 & 0 & 28650 \\
\hline Unit price & $\$ / \mathbf{k W}$ & 716 & & & \\
\hline \multirow{2}{*}{ Charge Controller } & \multicolumn{2}{|c|}{ kW } & 0 & 40 & 40 \\
\hline & \multicolumn{2}{|c|}{$\$$} & 0 & 10681 & 10681 \\
\hline Unit price & $\$ / \mathbf{k W}$ & 267 & & & \\
\hline \multirow{2}{*}{ Hybrid inverter } & \multicolumn{2}{|c|}{$\mathbf{k W n}$} & $\overline{0}$ & 20 & 20 \\
\hline & \multicolumn{2}{|c|}{$\$$} & 0 & 10899 & 10899 \\
\hline Unit price & $\$ / \mathbf{k W}$ & 545 & & & \\
\hline \multirow{2}{*}{ Combiner Box } & \multicolumn{2}{|c|}{$\mathrm{kW}$} & 40 & 0 & 40 \\
\hline & \multicolumn{2}{|c|}{$\$$} & 11320 & 0 & 11320 \\
\hline Unit price & $\$ / \mathbf{k W}$ & 283 & & & \\
\hline Total & \multicolumn{2}{|c|}{$\$$} & 39970 & 35582 & 75552 \\
\hline
\end{tabular}

The financial Figure $\mathrm{s}$ as a summary for DC-coupled and ACcoupled mini-grids are given in Table 5. In Solab case, ACcoupled network has slightly higher relevant investment cost. However, DC-coupled mini-grid has initial investment requirement, including the existing and relevant components, slightly higher. The reason behind this unexpected situation is the existing charge controllers reducing the relevant cost of DCcoupled mini-grids.

The comparable cost Figure s for DC-coupled and AC-coupled mini-grids are in parallel with the practical experiences published by USAID and ARE [7]. The difference in the operating expenses (OPEX) is originated from the replacement cost of batteries.

Despite of having longer lifetime of batteries in DCcoupled mini-grids (3.79 years in Zone 1, 5.37 years in Zone 2 in comparison to 3.21 years in AC-coupled minigrid), their larger total capacity leads to the greater replacement cost and thus operating expense. The final implication of the overall effects is the levelized cost of electricity which is 0.5 USD cents / $\mathrm{kWh}$ lower in ACcoupled mini-grid. 



Figure 6: Monthly Electricity Utilization over a Year in Solab with DC-Coupled Networks

Table 5: Summary of the Comparison between AC-Coupled and DC-Couple Mini-Grid Networks

\begin{tabular}{|l|c|c|c|c|c|}
\hline Quantity & Units & AC-coupled & DC-coupled & DC-coupled2 & DC-coupled \\
Initial Investment & $\$$ & 186783 & 113604 & 75552 & 189156 \\
\hline Relevant Capex & $\$$ & 66856 & 28306 & 35582 & 63888 \\
\hline Diesel consumption & liter/year & 1069 & 974 & 409 & 1383 \\
Diesel cost & $\$$ /year & 1079 & 983 & 413 & 1396 \\
\hline CO2 Emissions & $\mathrm{kg} /$ year & 2815 & 2565 & 1077 & 3642 \\
\hline Opex & $\$ /$ year & 12991 & 9030 & 4295 & 13325 \\
LCOE & $\$ /$ kWh & 0.303 & 0.318 & 0.293 & \\
Weighted LCOE & \$/kWh & 0.303 & & & 0.308 \\
Excess electricity & $\mathrm{kWh} /$ year & 36097 & 20278 & 15986 & 36264
\end{tabular}

\section{Conclusion}

The evolution of electricity networks from multiple standalone systems to AC-coupled and DC-coupled mini-grids has been studied for Solab. The base case, multiple standalone systems, has been proven to operate at the lowest efficiency due to the unavailability of interaction among centers. The efficiency of electricity utilization is proposed to be increased by valorizing the excess electricity within a mini-grid which will lead to savings in diesel consumption. In both cases, the simple payback time is slightly higher than 5 years. In the UAE, there exist lots of instances of setup which are currently working on standalone diesel genset. Example of these can be huge advertisement billboards on the highways, telephone towers of Etisalat and du in the middle of desert, mountains and highways, manmade island developments in Dubai, Abu Dhabi, labour and staff accommodations for temporary sites like Highway maintenance in almost all the emirates of the UAE. If the careful implementation of the Solar Hybrid power system is carried out; this system can prove to be beneficial and eco-friendly alternative which can be smartly used for the transition from the conventional to renewable energy source.

\section{References}

[1] O. Chebab, A. Atilaksana, and V. Wachenfald, "Fuel saving PV-Diesel sysems cost efficient use of solar energy” RE Asia Conference, 2012.

[2] "Clean and Renewable Energy",UAE State of Energy Report, 2015

[3] P. Jacquin, "Social, economic and organizational framework for sustainable operation of PV hybrid systems within mini-grids" Report IEA-PVPS T1105, 2011.

[4] L. Arribas, G. Bopp and M. Vetter, "World-wide overview of design and simulation tools for hbrid PV systems', Report IEA-PVPS T11-01, 2011.

[5] Alliance for Rural Electrification, "Hybrid power systems based on renewable energies: a sustainable and cost competitive solution for rural electrification" 2011.

[6] Schneider Electric, " AC coupling of inverters" Application note Rev A, 2010.

[7] S. Rolland and G. Glania, "Hybrid mini-grids for rural electrification: lessons learned" Allaince for Rural Electrification, March 2011. 